\title{
2-Naphthalenesulfonyl as a Tosyl Substitute for Protection of Amino F unctions. Cyclic Voltammetry Studies on Model Sulfonamides and Their Preparative Cleavage by Reduction ${ }^{\dagger}$
}

\author{
Barthélémy Nyasse, ${ }^{\ddagger \S}$ Leif Grehn, ${ }^{\S}$ Hernani L. S. Maia," Luis S. Monteiro," and \\ UIf Ragnarsson $*, \S$ \\ Department of Organic Chemistry, Faculty of Science, University of Yaoundél, \\ Box 812, Yaoundé, Cameroon, Department of Biochemistry, University of Uppsala, Biomedical Center, \\ PO Box 576, SE-751 23 Uppsala, Sweden, and Departamento de Quimica, Universidade do Minho, \\ Gualtar, P-4700-320 Braga, Portugal
}

Received April 26, 1999

\begin{abstract}
With the aim to develop a practically useful, reductively more labile alternative to tosyl for protection of amino functions, initially a number of $\mathrm{N}$-arenesulfonyl-protected heterocycles (pyrroles, imidazoles, indole, and carbazole) have been prepared and studied by cyclic voltammetry (CV). The recorded activation potentials vary from -1.32 to $-1.99 \mathrm{~V}$ (vs SCE). In N-sulfonylazol ides such as tosylindole the cathodic potentials are shifted by over $0.5 \mathrm{~V}$ compared to simple sulfonamides. An additional effect of the sulfonic acid component is also indicated. Among the compounds studied, 1- and 2-naphthalenesul fonylindole give CV peaks at about 0.4 and $0.2 \mathrm{~V}$, respectively, less negative potential than tosylindole. To further investigate naphthalenesulfonyl for this purpose, we have also prepared a variety of simple 1- and 2-naphthalenesulfonyl derivatives and studied them similarly. They have activation potentials above $-2.14 \mathrm{~V}$ and are all smoothly cleaved by $\mathrm{Mg} /$ $\mathrm{MeOH}$. The latter reagent is capable of cleaving $\mathrm{N}$-arenesulfonyl derivatives that give $\mathrm{CV}$ peaks above $-2.30 \mathrm{~V}$, whereas $\mathrm{Al}(\mathrm{Hg})$ requires potentials above about $-1.7 \mathrm{~V}$. Selective cleavage of 2-naphthalenesulfonyl in the presence of tosyl by $\mathrm{Mg} / \mathrm{MeOH}$ is demonstrated. Several examples of reductive cleavage of arenesulfonyl derivatives with $\mathrm{Mg} / \mathrm{MeOH}, \mathrm{Al}(\mathrm{Hg})$, and electrolysis on a preparative scale are given.
\end{abstract}

\section{Introduction}

The tosyl moiety is a classical and in many cases useful protecting group for various nitrogen functions, including amines. ${ }^{1}$ Nevertheless it is often not an ideal choice, because it normally requires drastic conditions for its cleavage so that many other sensitive functional groups, simultaneously present, are affected. Various approaches at eliminating this shortcoming, such as making it more labile to acid by introduction of suitable substituents in the benzene ring, were attempted and found to be useful. ${ }^{\text {la }}$ Several new alternative procedures for tosyl cleavage with the common feature that they shed light on relevant structural effects were al so proposed recently, using a wide variety of reagents such as $\mathrm{Sml}_{2},{ }^{2 a-c} \mathrm{Bu}_{3-}$ $\mathrm{SnH},{ }^{3}$ magnesium powder in methanol, ${ }^{4 a-c}$ lithium powder in the presence of naphthalene, 5 tetrabutylammonium fluoride, ${ }^{6}$ 2,2-dimethoxypropane, ${ }^{7}$ and iodotrimethyl-

* Corresponding author: fax: +46 185521 39; e-mail: urbki@ bmc.uu.se.

+ This paper is dedicated in friendship and with affection to Gotfryd Kupryszewski on the occasion of his 70th birthday.

₹ University of Yaoundé $\mathrm{l}$.

$\S$ University of Uppsala.

" Universidade do Minho.

(1) For an overview, see: (a) Greene, T. W.; Wuts, P. G. M. Protective Groups in Organic Chemistry, 3rd ed.; Wiley-Interscience: New York, 1999. (b) Kocienski, P. J . Protecting Groups; Thieme: New York, 1994 (2) (a) Vedejs, E.; Lin, S. J . Org. Chem. 1994, 59, 1602. (b) GoulaouicDubois, C.; Guggisberg, A.; Hesse, M. J . Org. Chem. 1995, 60, 5969. (c) Knowles, H.; Parsons, A. F.; Pettifer, R. M. Synlett 1997, 271.

(3) Parsons, A. F.; Pettifer, R. M. Tetrahedron Lett. 1996, 37, 1667.

(4) (a) Nyasse, B.; Grehn, L.; Ragnarsson, U. Chem. Commun. 1997,

1017. (b) Grehn, L.; Nyasse, B.; Ragnarsson, U. Synthesis 1997, 1429.

(c) Alonso, D. A.; Andersson, P. G. J. Org. Chem. 1998, 63, 9455.

(5) Alonso, E.; Ramon, D. J .; Y Yus, M. Tetrahedron 1997, 53, 14355.

(6) Yasuhara, A.; Sakamoto, T. Tetrahedron Lett. 1998, 39, 595. silane. ${ }^{8}$ Nevertheless, in our opinion there is still a need for improvements in this area, and we have therefore been engaged in the development of an alternative to tosyl that can be cleaved under milder conditions.

In connection with attempts to cleave tosyl reductively from various tosylcarbamates by $\mathrm{Mg} / \mathrm{MeOH}$, ${ }^{4 a}$ we also studied 1-tosylindole (1a) and found that, contrary to tosylamides in general, it was rapidly and completely cleaved, as briefly reported for a substituted 1-tosylindole derivative by Yokoyama et al. ${ }^{9}$ As we had previously investigated many arenesulfonamides and, especially, the corresponding tert-butyl sulfonylcarbamates by cyclic voltammetry (CV), ${ }^{10}$ we therefore determined the activation potential of compound $\mathbf{l a}$ by this technique. We obtained a value of $-1.96 \mathrm{~V}$ (vs SCE) as compared to $-2.52 \mathrm{~V}$ for tosylamide, which amply demonstrated the powerful influence of the indole moiety. Moreover, because benzenesulfonyl has been cleaved from a substituted pyrrole derivative with $\mathrm{Mg} / \mathrm{MeOH},{ }^{11}$ we decided to prepare a few additional $\mathrm{N}$-tosylated heterocycles to measure their activation potentials similarly. 695.

(7) Chandrasekhar, S.; Mohapatra, S. Tetrahedron Lett. 1998, 39,

(8) Sabitha, G.; Subba Reddy, B. V.; Abraham, S.; Yadav, J. S. Tetrahedron Lett. 1999, 40, 1569 and references therein.

(9) Yokoyama, Y.; Matsumoto, T.; Murakami, Y.J . Org. Chem. 1995, 60, 1486.

(10) (a) Grehn, L.; Gunnarsson, K.; Maia, H. L. S.; Montenegro, M. I.; Pedro, L.; Ragnarsson, U. J . Chem. Res. 1988, (S) 399; (M) 3081. (b) Maia, H. L. S.; Monteiro, L. S.; Degerbeck, F.; Grehn, L.; Ragnarsson, U.J . Chem. Soc., Perkin Trans. 2 1993, 495. (c) Nyasse, B.; Grehn, L.; Ragnarsson, U.; Maia, H. L. S.; Monteiro, L. S.; Leito, I.; Koppel, I.; Koppel, J . J . Chem. Soc., Perkin Trans. 1 1995, 2025 and references therein.

(11) Okabe, K.; Natsume, M. Tetrahedron 1991, 47, 7615. 
Table 1. CV Peak Potentials for Some N-Arenesulfonyland Two N-Aroyl-Protected Heterocycles ${ }^{a}$

\begin{tabular}{|c|c|c|}
\hline compd & arenesulfonyl derivative & $\begin{array}{l}-E_{P} b / N \\
(v s S C E)\end{array}$ \\
\hline la & 1-tosylindole & 1.96 \\
\hline $\mathbf{1 b}$ & 1-tosylpyrrole & 1.98 \\
\hline 1c & 1-tosylpyrrole-2-COOEtc & 1.86 \\
\hline 1d & 1-tosylimidazole & 1.84 \\
\hline le & 1-tosylbenzimidazole & 1.78 \\
\hline If & 1 -(4-fluorobenzenesulfonyl)-indolec & 1.99 \\
\hline 19 & 1-(1-naphthalenesulfonyl)-indole $e^{c}$ & 1.58 \\
\hline lh & 1-(2-naphthal enesulfonyl)-indolec & 1.75 \\
\hline $\mathbf{1 i}$ & 9-(2-naphthalenesulfonyl)-carbazol $e^{c}$ & 1.59 \\
\hline $\mathbf{1} \mathbf{j}$ & 1-dansylindole ${ }^{c}$ & 1.59 \\
\hline $\overrightarrow{\mathbf{l}} \mathbf{k}$ & 1-(4-cyanobenzenesulfonyl)-indol $e^{c}$ & 1.36 \\
\hline 11 & 9-(4-cyanobenzenesulfonyl)-carbazole $e^{c}$ & 1.32 \\
\hline $1 \mathrm{~m}$ & 1-benzoylindole & 1.91 \\
\hline \multirow[t]{2}{*}{ In } & 1-(1-naphthoyl)-indole & 1.74 \\
\hline & tosylamide & 2.52 \\
\hline
\end{tabular}

${ }^{\text {a }}$ All compounds prepared gave interpretable ${ }^{1} \mathrm{H}$ and ${ }^{13} \mathrm{C}$ NMR spectra. ${ }^{b}$ Cathode, vitreous carbon; solvent, DMF; supporting electrolyte, $\mathrm{Bu}_{4} \mathrm{NBF}_{4} 0.1 \mathrm{~mol} \mathrm{dm}{ }^{-3}$; substrate concentration, $\sim 0.005 \mathrm{~mol} \mathrm{dm}^{-3}$. c New compound which gave a satisfactory elemental analysis.

A reexamination of some electrochemical data in the light of our present experiences indicated that in the series of tert-butyl sulfonyl carbamates recently studied ${ }^{10 c}$ the peak potentials were shifted by $0.19-0.30 \mathrm{~V}$ in comparison with those of the related sulfonamides. On the other hand, within the same two series of compounds, the variations due to the arenesulfonyl moieties spanned 0.97 and $0.99 \mathrm{~V}$, respectively. Considering the effect of tert-butoxycarbonylation of arenesulfonamides with respect to their reductive cleavage as illustrated by $\mathrm{Mg} /$ $\mathrm{MeOH}$, ${ }^{4 a}$ we set out to find an inexpensive alternative to tosyl that would not require tert-butoxycarbonylation of the sulfonamide but would allow reductive cleavage of the sulfonamide itself. In this paper we present two moieties that both seem to chemically fulfill these requirements, i.e., 1- and 2-naphthalenesulfonyl, of which the latter is the least expensive in use. As will be seen below, these groups first came out from the heterocycle work.

\section{Results and Discussion}

To explore the effect of the heterocyclic and the arenesulfonyl parts of the molecules on the activation potentials as determined by CV, a few tosylated derivatives $(\mathbf{l b}-\mathbf{e})$, other sulfonylated indoles $(\mathbf{1 f}-\mathbf{h}, \mathbf{j}, \mathbf{k})$, and two carbazol es $(\mathbf{1 i}, \mathbf{I})$ were prepared. ${ }^{12}$ These substances are listed in Table 1 together with their activation potentials $\left(E_{p}\right)$.

As shown in Table 1, compounds $\mathbf{1 b}-\mathbf{e}$ all displayed CV peaks at about the same or slightly higher (less negative) potential as that of $\mathbf{1 a}$, i.e., the constituent $\mathrm{N}$-heterocycles lowered the cathodic potentials by $0.54-$ $0.74 \mathrm{~V}$ in comparison with unsubstituted tosylamide. Because nevertheless some minor influence of el ectron delocalization was indicated in these experiments, we decided to extend our work and make three simple, readily accessible naphthalenesulfonyl indoles $(\mathbf{1 g}, \mathbf{h}, \mathbf{j})$.

(12) All new compounds in Table 1 were made under phase-transfer catalysis conditions with tetrabutylammonium hydrogen sulfate as catalyst in benzene with solid $\mathrm{NaOH} / \mathrm{K}_{2} \mathrm{CO}_{3}(\mathbf{l c}$, $\mathbf{i}$, and $\mathbf{I})$ or $50 \%$ $\mathrm{KOH}$ as base (1e-h, j, and $\mathbf{k})$. They were all obtained as crystalline solids. For a typical procedure used, see: Hodson, H. F.; Madge, D. J .; Slawin, A. N. Z.; Widdowson, D. A.; Williams, D. J . Tetrahedron 1994 50, 1899.
These were found to give peaks at higher potentials than those of $\mathbf{1 b}-\mathbf{e}, 0.77-0.94 \mathrm{~V}$ higher than that of tosylamide. Finally, 1-(4-cyanobenzenesulfonyl)-indole (1k) and 9-(4-cyanobenzenesulfonyl)-carbazole (11) were al so made and studied. As could be expected from our previous work, ${ }^{10 c}$ their CV peaks were further shifted in comparison with the previously discussed compounds (to -1.36 and $-1.32 \mathrm{~V}$, respectively). These syntheses were afterward followed up with 9-(2-naphthalenesulfonyl)-carbazole (1i), which was used in the preparative cleavage experiments below.

Results such as those described in Table 1, together with previously available data, allow some conclusions to be drawn. Because, in addition to the el ectronic effects of substituents in the arenesulfonyl group observed earlier, ${ }^{10 c}$ the aromatic systems and the amine moieties obviously have a significant influence on the activation potential of sulfonamides as measured by CV, a wide variation in stability of sulfonamides toward reduction should be expected. This must be kept in mind in the fine-tuning of such protecting groups. Series of compounds with known activation potentials are obviously useful in determining the scope of various reducing agents. Because seven of the $\mathrm{N}$-arenesulfonyl carbamates cleaved by magnesium powder in methanol ${ }^{4 a}$ had earlier been studied by $\mathrm{CV}$ and found to give peaks in the range from -1.44 to $-2.28 \mathrm{~V}$, $10 \mathrm{c}$ at this stage it appears that $\mathrm{Mg} / \mathrm{MeOH}$ is able to efficiently cleave compounds with activation potentials down to about $-2.3 \mathrm{~V}$ (Vs SCE), i.e., close to the normal potential of magnesium, whereas for mercury-activated aluminum, as judged from the compounds studied in this paper, the corresponding value seems to be -1.7 to $-1.8 \mathrm{~V}$.

As shown in Table 1, 1- and 2-naphthalenesulfonyl derivatives of indole have activation potentials $0.2-0.4$ $\mathrm{V}$ higher than that of tosylindole, corresponding approximately to the effect of the carbamate contribution in arenesulfonylcarbamates. ${ }^{10 c}$ Therefore, a number of model sulfonamides derived from them have been prepared, studied by CV, and subsequently used in deprotection experiments (Table 2 ).

I nspection of Table 2 shows that, for the three pairs of 1- and 2-naphthalenesulfonyl derivatives made (a, $\mathbf{b}$, and e), the activation potentials are higher within the former series but that the differences are at the most $0.11 \mathrm{~V}$. Larger differences in this respect exist between the isopropylamides and anilides ( 0.19 and $0.23 \mathrm{~V}$, respectively) and, especially, between the isopropylamides and indole derivatives ( $\mathbf{l g}$ and $\mathbf{h}$, Table 1; 0.45 and $0.39 \mathrm{~V}$, respectively). The activation potentials for the hydrazines are close to those of the anilides. In the remaining compounds studied, the 2-naphthalenesulfonyl groups are attached to aliphatic nitrogens, as a consequence of which their activation potentials approach those of $\mathbf{3 a}$ and $3 f$.

All experimental potentials measured for $\mathbf{2}$ and $\mathbf{3}$ are well above $-2.30 \mathrm{~V}$. Consequently, with $\mathrm{Mg} / \mathrm{MeOH}$ these compounds should cleave, and we have confirmed chromatographically that they do so completely within 60 $\mathrm{min}$. As a rule, these reactions were carried out under ultrasonic conditions, and spontaneous evolution of gas was initiated within a few min. Nonvolatile amines could generally be isolated in over $90 \%$ yields (Table 2 ). Similar results were obtained under simple stirring conditions, but in this case activation of the metal by addition of at least catalytic amounts of $\mathrm{NH}_{4} \mathrm{Cl}^{11}$ was required. $\mathrm{NH}_{4-}^{-}$ 
Table 2. CV Peak Potentials and Yields on Mg/MeOH Reduction of Some Naphthalenesulfonamides ${ }^{a}$

\begin{tabular}{|c|c|c|c|c|}
\hline compd & naphthalenesulfonamide & $-E_{p}^{b}(v S S C E)$ & time (min) & yieldc $(\%)$ \\
\hline $2 a$ & $\mathrm{~N}$-isopropyl-1-naphthalenesulfonamide ${ }^{d}$ & 2.03 & 55 & e \\
\hline 3a & $\mathrm{N}$-isopropyl-2-naphthalenesulfonamide ${ }^{\mathrm{d}}$ & 2.14 & 60 & $\mathrm{e}$ \\
\hline $\mathbf{2 b}$ & 1-naphthalenesulfonanilide ${ }^{d}$ & 1.84 & 40 & 96 \\
\hline \multirow[t]{2}{*}{ 3b } & 2-naphthalenesulfonanilide ${ }^{d}$ & 1.91 & 45 & 94 \\
\hline & Ts-anilide & 2.18 & & \\
\hline \multirow[t]{2}{*}{ 3c } & $\mathrm{N}$-benzyl-2-naphthalenesulfonamide ${ }^{\mathrm{d}}$ & 2.05 & 60 & e \\
\hline & N-benzyl-Ts-amide & 2.41 & & \\
\hline 3d & N-benzyl-N-methyl-2-naphthalenesulfonamidef & 1.96 & 60 & $\mathrm{e}$ \\
\hline $\mathbf{2 e}$ & 1-naphthalenesulfonyl-NHNH-Cbz & 1.87 & 40 & 90 \\
\hline 3e & 2-naphthalenesulfonyl-NHNH-Cbz & 1.89 & 50 & 92 \\
\hline $3 f$ & 2-naphthalenesulfonyl-NH( $\left(\mathrm{CH}_{2}\right)_{2} \mathrm{NH}-\mathrm{Ts}^{f}$ & $\begin{array}{r}2.02 / 1 \\
\sim 2.48\end{array}$ & 40 & 93 \\
\hline 3g & 2-naphthalenesulfonyl-L-phenylalaninef & 1.97 & 60 & $\mathrm{e}$ \\
\hline $3 \mathbf{h}$ & 2-naphthal enesulfonyl-L-phenylalanine Me ester ${ }^{f}$ & 2.02 & 45 & 86 \\
\hline
\end{tabular}

a All compounds prepared gave interpretable ${ }^{1} \mathrm{H}$ and ${ }^{13} \mathrm{C}$ NMR spectra. ${ }^{b}$ Cathode, vitreous carbon; solvent, DMF; supporting electrolyte, $\mathrm{Bu}_{4} \mathrm{NBF}_{4} 0.1 \mathrm{~mol} \mathrm{dm}^{-3}$; substrate concentration, $\sim 0.005 \mathrm{~mol} \mathrm{dm}{ }^{-3}$. ${ }^{c}$ Reductions performed under sonication with 10 equiv of $\mathrm{Mg}$ powder in $\mathrm{MeOH}$, generally on a $1 \mathrm{mmol}$ scale. TLC indicated that all starting material reacted. ${ }^{\mathrm{d}}$ Compound previously reported. Mp recorded: 124-125 ${ }^{\circ} \mathrm{C}$ (2a); $114-115^{\circ} \mathrm{C}$ (3a); $157-159{ }^{\circ} \mathrm{C}$ (2b); $130-131{ }^{\circ} \mathrm{C}$ (3b); $120.5-122{ }^{\circ} \mathrm{C}$ (3c); from EtOAc/heptane (2/3a and b) or EtOAcl light petroleum (3c). ${ }^{\text {eTLC }}$ indicated that all starting material had reacted; no yields were determined owing to the volatility of the products (or zwitterionic character of the product in the experiment with $\mathbf{3 g}$ ). ${ }^{\mathrm{f}} \mathrm{N}$ ew compound which gave a satisfactory elemental analysis. Mp recorded: $94-95^{\circ} \mathrm{C}$ (3d); $149-149.5^{\circ} \mathrm{C}$ (2e); $129.5-130.5^{\circ} \mathrm{C}$; (3e); $173-175^{\circ} \mathrm{C}$ (3f); $148-149{ }^{\circ} \mathrm{C}(3 \mathrm{~g}) ; 159-160{ }^{\circ} \mathrm{C}(3 \mathrm{~h}) ;$ from EtOACl light petroleum (3d), $\mathrm{CH}_{2} \mathrm{Cl}_{2} /\left(\mathrm{C}_{2} \mathrm{H}_{5}\right)_{2} \mathrm{O}(\mathbf{2} / 3 \mathbf{e})$, EtOAC (3f and $\mathbf{h}$ ) or EtOAc/heptane (3g).

$\mathrm{Cl}$, however, consumes significant amounts of magnesium, and therefore after $1 \mathrm{~h}$, according to TLC, sometimes as much as $50 \%$ of the starting material remained, requiring the addition of more magnesium. We have found that typically a total reaction time of $4 \mathrm{~h}$ and several magnesium additions (up to a total of 20 equiv) were required to drag reductions to completion under these conditions. This would explain the large amount of magnesium used to cleave the pyrrole derivative in the pioneering work by Okabe and Natsume. However, in the case of our hydrazine derivatives (2/3e), cleaner reaction mixtures were obtained when reactions were carried out under ultrasonic conditions in the presence of this additive but the yields obtained were the same. We anticipate that $\mathrm{NH}_{4} \mathrm{Cl}$ can occasionally have a favorable effect by lowering the basicity of the reaction medium. The increased lability of 2-naphthal enesulfonyl in relation to tosyl is highlighted in the data for $\mathbf{3 f}$ and

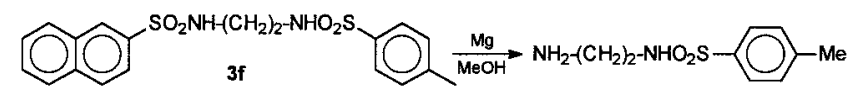

its clean selective cleavage with $\mathrm{Mg} / \mathrm{MeOH}$ as described at the end of the Experimental Section. No trace of starting material was visible chromatographically in the deavage product. More importantly, no significant byproduct(s) could be detected in this key experiment.

Several further cleavage experiments on compounds 1-3 have been performed. Because the activation potentials of benzamides and benzoyl carbamates as measured by $\mathrm{CV}$ are similar to those of tosylamides and tosylcarbamates, ${ }^{10 \mathrm{~b}}$ we also prepared 1-benzoylindole (Im) and found that it gave a CV peak at $-1.91 \mathrm{~V}$, i.e., at about the same potential as that of $\mathbf{1 a}$. It could also be cleaved by magnesium powder in methanol, but because acylindoles are known to cleave under basic conditions, in this case a control experiment was also carried out which showed that $1 \mathrm{~m}$ with amide absorption at $1677 \mathrm{~cm}^{-1}$ is cleaved by $\mathrm{Mg}(\mathrm{OMe})_{2}$ al one In compound In the CV peak is shifted to $-1.74 \mathrm{~V}$, i.e., a slightly more negative value than that for $\mathbf{1 g}$. Its amide absorption band appears at $1697 \mathrm{~cm}^{-1}$, i.e., closer to the ester region, indicating an additional effect of 1-naphthyl in comparison with phenyl.
Recently, in connection with work on multisubstituted hydrazines, ${ }^{13}$ we made extensive use of the previously studied 4-cyanobenzenesulfonyl protecting group, ${ }^{10 c}$ which could be cleaved under very mild reductive conditions with mercury-activated aluminum [Al( $\mathrm{Hg})$ ] in $92-99 \%$ yield. Therefore preparative cleavage experiments with $\mathbf{1 k}$ and $\mathbf{1 l}$ using this procedure have now also been undertaken. Both compounds were cleaved, and from the latter carbazole was isolated in quantitative yield, whereas that of indole was a bit lower. It should be noted in this context that the three naphthalenesulfonylazolides $\mathbf{1 g}-\mathbf{i}$ and in fact 1c could al so be deprotected with $\mathrm{Al}(\mathrm{Hg})$, but a larger excess of reducing agent was required for complete cleavage in these cases. However, despite a very large excess of reagent (60 equiv), this procedure failed to cleave 1a, as only a minor amount of indole was detected in the crude reaction mixture. We therefore believe that $\mathrm{Al}(\mathrm{Hg})$ is going to be a useful, milder alternative to $\mathrm{Mg} / \mathrm{MeOH}$ for cleavage of certain compounds of this type. For comparison, a few successful preparative electrolysis experiments were also carried out at potentials just below that of the $\mathrm{CV}$ peaks, thus testifying to the significance of the data in Table 1. Also, with this method $\mathbf{1}$ was cleaved and subsequently carbazole was isolated in quantitative yield. Because of its simplicity and mildness, cathodic reduction should, of course, always be kept in mind in this context. Only further work will tell us the relative merits of the discussed cleavage procedures.

\section{Conclusions}

In this paper we have explored $\mathrm{CV}$ as a tool for investigating the cathodic stability of various sulfonyl moieties attached to nitrogen. This allowed us to correlate semiquantitatively the effect of structure with the performance of $\mathrm{Mg} / \mathrm{MeOH}$ as a reducing agent for sulfonamides and to develop naphthal enesulfonyl for protection of amino groups. Naphthalenesulfonamides are significantly more easily reduced than tosylamides and can be

(13) Grehn, L.; Lönn, H.; Ragnarsson, U. Chem. Commun. 1997, 
cleaved efficiently by $\mathrm{Mg} / \mathrm{MeOH}$ within $1 \mathrm{~h}$ under ultrasonic conditions or by simple stirring, especially when the metal has been activated by addition of $\mathrm{NH}_{4} \mathrm{Cl}$. Ordinary tosylamides are stable under these conditions and require prior conversion to tosylcarbamates to be cleaved. Of the two required reagents, 2-naphthalenesulfonyl chloride is particularly inexpensive. As we have not noticed any significant difference in the reactivities between 1- and 2-naphthal enesulfonyl groups so far, at this stage we prefer to use the latter instead of tosyl as an amino protecting group.

\section{Experimental Section}

General. All melting points were determined on a Gallenkamp melting point apparatus and are uncorrected. TLC analyses were carried out on $0.25-\mathrm{mm}$-thick precoated silica plates (Merck Fertigplatten Kieselgel $60 \mathrm{~F}_{254}$ ) using systems (A) toluene/MeCN 2:1, (B) light petroleum/Et ${ }_{2} \mathrm{O} 2: 1$, and (C) $\mathrm{CH}_{2} \mathrm{Cl}_{2} / \mathrm{Me}_{2} \mathrm{CO} / \mathrm{HOAc} 40: 10: 1$. Spots were visualized under UV light or, for hydrazines preferentially, by alcoholic $\mathrm{H}_{7-}$ $\left[\mathrm{P}\left(\mathrm{MO}_{2} \mathrm{O}_{7}\right)_{6}\right]$ spray and subsequent heating (blue spots). Preparative chromatography was carried out on Merck Kieselgel 60 (70-230 mesh). Magnesium slurries were subjected to ultrasound treatment at $35 \mathrm{kHz} / 120-240 \mathrm{~W}$ (Bandelin, Berlin, type RK 106) at room temperature. ${ }^{1} \mathrm{H}$ and ${ }^{13} \mathrm{C}$ NMR spectra were recorded at 400 and $100.4 \mathrm{MHz}$ in $\sim 5 \% \mathrm{CDCl}_{3}$ solution at $25^{\circ} \mathrm{C}$, unless otherwise stated. All shifts are given in $\delta$ ppm using $\delta_{\mathrm{H}}(\mathrm{TMS})=0$ and $\delta_{\mathrm{C}}\left(\mathrm{CDCl}_{3}\right)=77.02$, respectively, as reference. Assignments were made by comparison of chemical shifts and peak multiplicities. Elemental analyses of crystalline derivatives were carried out by Mikro Kemi $A B$ (Uppsala)

1-(2-Naphthalenesulfonyl)-indole (1h). (Typical Procedure). Compound $\mathbf{T h}$ was made from indole $(1.17 \mathrm{~g}, 10$ $\mathrm{mmol})$ and 2-naphthalenesulfonyl chloride $(2.38 \mathrm{~g}, 10.5$ $\mathrm{mmol}$ ) in benzene in the presence of TBAHS (250 mg) and 50\% $\mathrm{KOH}(\mathrm{w} / \mathrm{v} ; 15 \mathrm{~mL})$ by stirring for $3 \mathrm{~h}$. Water containing $\mathrm{NaCl}$ was added, and the benzene separated, whereupon it was washed with water (three times) and dried $\left(\mathrm{MgSO}_{4}\right)$. After evaporation, the crude solid was recrystallized from EtOH to give 1h $(2.27 \mathrm{~g}, 74 \%)$ : $\mathrm{mp} 101-102.5^{\circ} \mathrm{C}$; pure by TLC (UV; A); ${ }^{1} \mathrm{H}$ NMR $\left(400 \mathrm{MHz}, \mathrm{CDCl}_{3}\right) \delta 6.66\left(\mathrm{dd}, \mathrm{J}_{1}=3.7 \mathrm{~Hz}, \mathrm{~J}_{2}=\right.$ $0.7 \mathrm{~Hz}, 1 \mathrm{H}$ ), 7.20 (perturbed dt, J $1 \approx 7.5 \mathrm{~Hz}, \mathrm{~J}_{2} \approx 1.1 \mathrm{~Hz}, 1$ $\mathrm{H}$ ), 7.32 (pert. dt, J $1 \approx 7.8 \mathrm{~Hz}, \mathrm{~J}_{2} \approx 1.3 \mathrm{~Hz}, 1 \mathrm{H}$ ), 7.50 (pert. $\mathrm{dt}$, J $\mathrm{I}_{1}=7.7 \mathrm{~Hz}, \mathrm{~J}_{2} \approx 1 \mathrm{~Hz}, 1 \mathrm{H}$ ), 7.56 and 7.59 (2 overlapping $\mathrm{dt}$, J $\left.{ }_{1} \approx 7 \mathrm{~Hz}, \mathrm{~J}_{2} \approx 1.6 \mathrm{~Hz}, 1 \mathrm{H}+1 \mathrm{H}\right), 7.64(\mathrm{~d}, \mathrm{~J}=3.7 \mathrm{~Hz}, 1$ H), 7.75 (dd, J $1=8.8 \mathrm{~Hz}, J_{2}=2.0 \mathrm{~Hz}, 1 \mathrm{H}$ ), 7.80 (pert. t, J $\approx$ $9 \mathrm{~Hz}, 2 \mathrm{H}$ ), 7.93 (pert. dd, J $1=7.4 \mathrm{~Hz}, \mathrm{~J}_{2} \approx 1.6 \mathrm{~Hz}, 1 \mathrm{H}$ ), 8.06 $\left(\mathrm{dd}, \mathrm{J}_{1}=8.3 \mathrm{~Hz}, \mathrm{~J}_{2} \approx 0.8 \mathrm{~Hz}, 1 \mathrm{H}\right.$ ), 8.52 (pert. $\mathrm{d}, \mathrm{J} \approx 2 \mathrm{~Hz}, 1$ $\mathrm{H}) ;{ }^{13} \mathrm{C} N M R\left(100.4 \mathrm{MHz}, \mathrm{CDCl}_{3}\right) \delta 109.21,113.51,121.41$, $121.44,123.34,124.64,126.39,127.76,127.88,128.55$, 129.37, $129.44,129.68,130.74,131.86,134.84,135.11,135.19$. Anal. Calcd for $\mathrm{C}_{18} \mathrm{H}_{13} \mathrm{NO}_{2} \mathrm{~S}$ : C, 70.34; $\mathrm{H}, 4.26 ; \mathrm{N}, 4.56$. Found: $\mathrm{C}$, 70.6; $\mathrm{H}, 4.3 ; \mathrm{N}, 4.6$.

9-(2-Naphthalenesulfonyl)-carbazole (1i). (Alternative Procedure). Carbazole $(1.67 \mathrm{~g}, 10 \mathrm{mmol})$ in benzene $(40 \mathrm{~mL})$ was treated with freshly ground $\mathrm{NaOH}(0.60 \mathrm{~g}, 15 \mathrm{mmol})$, dry $\mathrm{K}_{2} \mathrm{CO}_{3}(4.14 \mathrm{~g}, 30 \mathrm{mmol})$, and TBAHS $(0.68 \mathrm{~g}, 2.0 \mathrm{mmol})$ in one portion with vigorous stirring. After a few minutes, 2-naphthalenesulfonyl chloride $(3.40 \mathrm{~g}, 15 \mathrm{mmol}$ ) in benzene $(25 \mathrm{~mL}$ ) was added dropwise, and the mixture was left with stirring overnight, at which time TLC (A) indicated complete reaction. Most of the solvent was stripped off at reduced pressure, and the solid residue was partitioned between EtOAC and $1 \mathrm{M} \mathrm{KHSO}_{4}$. The organic extract was washed with $1 \mathrm{M}$ $\mathrm{KHSO}_{4}, 1 \mathrm{M} \mathrm{NaHCO}_{3}$, and brine and dried $\left(\mathrm{Na}_{2} \mathrm{SO}_{4}\right)$. Removal of the solvent left a white solid $(3.50 \mathrm{~g}, 98 \%)$ : pure by TLC (A); heavy, lustrous crystals; mp $169-170{ }^{\circ} \mathrm{C}$ [from EtOAd light petroleum 1:1 $(80 \mathrm{~mL} / \mathrm{g})$ ]; ${ }^{1} \mathrm{H} \mathrm{NMR}\left(400 \mathrm{MHz}, \mathrm{CDCl}_{3}\right) \delta$ 7.32 (dt, J ${ }_{1}=7.5 \mathrm{~Hz}, \mathrm{~J}_{2} \approx 1 \mathrm{~Hz}, 2 \mathrm{H}$ ), $7.45-7.52$ (compl. sign., $4 \mathrm{H}$ ), 7.64 (pert. $d, J \approx 0.5 \mathrm{~Hz}, 2 \mathrm{H}$ ), $7.66-7.68$ (compl. sign., $1 \mathrm{H}$ ), 7.82 (pert. dd, J $1 \approx 7 \mathrm{~Hz}, \mathrm{~J}_{2} \approx 2 \mathrm{~Hz}, 1 \mathrm{H}$ ), 7.85 (ddd, J $\left.=7.7 \mathrm{~Hz}, \mathrm{~J}_{2}=1.3 \mathrm{~Hz}, \mathrm{~J}_{3} \approx 0.7 \mathrm{~Hz}, 2 \mathrm{H}\right), 8.40\left(\mathrm{dt}, \mathrm{J}_{1}=8.4 \mathrm{~Hz}\right.$, $\mathrm{J}_{2} \approx 0.7 \mathrm{~Hz}, 2 \mathrm{H}$ ), 8.46 (pert. $\left.\mathrm{d}, \mathrm{J} \approx 1 \mathrm{~Hz}, 1 \mathrm{H}\right) ;{ }^{13} \mathrm{C}$ NMR $(100.4$ $\left.\mathrm{MHz} \mathrm{CDCl}_{3}\right) \delta 115.10,120.02,121.20,123.95,126.35,127.42$, $127.56,127.73,128.22,129.11,129.40,129.43,131.66,134.85$, 135.18, 138.38. Anal. Calcd for $\mathrm{C}_{22} \mathrm{H}_{15} \mathrm{NO}_{2} \mathrm{~S}: \mathrm{C}, 73.93 ; \mathrm{H}, 4.23$; $\mathrm{N}$, 3.92. Found: $\mathrm{C}, 73.8 ; \mathrm{H}, 4.2 ; \mathrm{N}, 3.9$.

2-Naphthalenesulfonanilide (3b). (Typical Procedure). Aniline (465 mg, $5.0 \mathrm{mmol})$ in $\mathrm{CH}_{2} \mathrm{Cl}_{2}(100 \mathrm{~mL})$ was chilled in ice with the exclusion of moisture, and then triethylamine (550 $\mathrm{mg}, 5.45 \mathrm{mmol}$ ) was added. The resulting solution was treated dropwise under stirring with 2-naphthalensulfonyl chloride $(1.13 \mathrm{~g}, 5 \mathrm{mmol})$ also dissolved in $\mathrm{CH}_{2} \mathrm{Cl}_{2}(30 \mathrm{~mL})$ over $1 \mathrm{~h}$ at $0{ }^{\circ} \mathrm{C}$, and the mixture was left overnight at ambient temperature. After concentration to ca. $30 \mathrm{~mL}$ the solution was partitioned between EtOAc $(150 \mathrm{~mL})$ and $1 \mathrm{M} \mathrm{KHSO}_{4}(50 \mathrm{~mL})$, and the organic phase was washed successively with $1 \mathrm{M}$ $\mathrm{KHSO}_{4}, 1 \mathrm{M} \mathrm{NaHCO}_{3}$, and brine (three times each). The extract was dried $\left(\mathrm{Na}_{2} \mathrm{SO}_{4}\right)$ and then evaporated to give $\mathbf{3 b}$ as a white solid $(1.35 \mathrm{~g}, 95 \%)$. The product was recrystall lized first from EtOAc/heptane and then from EtOH to give small needles: $\mathrm{mp} 132.5-133.5^{\circ} \mathrm{C}$ (lit. ${ }^{14} \mathrm{mp} 132{ }^{\circ} \mathrm{C}$ ); ${ }^{1} \mathrm{H}$ NMR (400 $\mathrm{MHz}, \mathrm{CDCl}_{3}$ ) $\delta$ 7.04-7.08, 7.11-7.13 and 7.17-7.21 (compl. sign., $1 \mathrm{H}+2 \mathrm{H}+2 \mathrm{H}$ ), 7.31 (br s, $1 \mathrm{H}$ ), 7.54 (pert. dt, J $1 \approx$ $7.4 \mathrm{~Hz}, J_{2} \approx 1.4 \mathrm{~Hz}, 1 \mathrm{H}$ ), 7.60 (pert. dt, J 1 ₹ $7.5 \mathrm{~Hz}, \mathrm{~J}_{2} \approx 1.4$ $\mathrm{Hz}, 1 \mathrm{H}), 7.79\left(\mathrm{dd}, \mathrm{J}_{1}=8.7 \mathrm{~Hz}, \mathrm{~J}_{2}=1.9 \mathrm{~Hz}, 1 \mathrm{H}\right), 7.84$ and 7.86 (2 overlapping d, J $\approx 8.7 \mathrm{~Hz}, 1 \mathrm{H}+2 \mathrm{H}$ ), 8.39 (pert. d, J $=1.5 \mathrm{~Hz}, 1 \mathrm{H}) ;{ }^{13} \mathrm{C} \mathrm{NMR}\left(100.4 \mathrm{MHz} \mathrm{CDCl}_{3}\right) \delta 121.60,122.22$, $125.38,127.49,127.84,128.90,129.29,129.31,129.41,131.99$, $134.89,135.89,136.39$.

1-(2-Naphthalenesulfonyl)-NH( $\left(\mathrm{CH}_{2}\right)_{2} \mathrm{NH}-\mathrm{Ts}$ (3f). This compound was made from Ts- $\mathrm{NH}\left(\mathrm{CH}_{2}\right)_{2} \mathrm{NH}_{2}(1.07 \mathrm{~g}, 5 \mathrm{mmol})$ and 2-naphthalensul fonyl chloride (1.13 g, $5 \mathrm{mmol}$ ) in $\mathrm{CH}_{2} \mathrm{Cl}_{2}$ in the presence of triethylamine $(550 \mathrm{mg}, 5.45 \mathrm{mmol})$. After the reaction was allowed to proceed overnight at ambient temperature as for $\mathbf{3 b}$, a white precipitate was formed. The mixture was then filtered, and the resulting white solid obtained was washed five times with EtOAc before it was recrystallized from EtOAc/light petroleum to afford $3 f$ (1.90 g, 94\%): mp 173-175 ${ }^{\circ} \mathrm{C} ;{ }^{1} \mathrm{H}$ NMR (400 MHz, DMSO-d 6 ) $\delta$ $2.30(\mathrm{~s}, 3 \mathrm{H}), 2.73$ and $2.78(2 \mathrm{~m}, 2 \mathrm{H}+2 \mathrm{H}), 7.26$ and 7.54 $(2 \mathrm{~d}, \mathrm{~J}=8.2 \mathrm{~Hz}, 2 \mathrm{H}+2 \mathrm{H}), 7.60(\mathrm{brt}, \mathrm{J} \approx 5.7 \mathrm{~Hz}, 1 \mathrm{H}), 7.68$ and $7.72\left(2 \mathrm{dt}, \mathrm{J}_{1}=6.9 \mathrm{~Hz}, \mathrm{~J}_{2} \approx 1 \mathrm{~Hz}, 1 \mathrm{H}+1 \mathrm{H}\right), 7.76(\mathrm{dd}$, J $\left.=8.8 \mathrm{~Hz}, \mathrm{~J}_{2}=1.8 \mathrm{~Hz}, 1 \mathrm{H}\right), 7.81(\mathrm{brt}, \mathrm{J} \approx 5.7 \mathrm{~Hz}, 1 \mathrm{H}), 8.05$ and $8.16(2$ pert. $d, J \approx 7.7 \mathrm{~Hz}, 1 \mathrm{H}+1 \mathrm{H}), 8.12(\mathrm{~d}, \mathrm{~J}=8.6$ $\mathrm{Hz}, 1 \mathrm{H}), 8.40(\mathrm{~d}, \mathrm{~J} \approx 1.5 \mathrm{~Hz}, 1 \mathrm{H}) ;{ }^{13} \mathrm{C} N M R(100.4 \mathrm{MHz}$, DMSO-d $\left.\mathrm{d}_{6}\right) \delta 20.86,42.12,42.14,122.08,126.33,127.32,127.58$, $127.81,128.72,129.17,129.41,129.52,131.66,134.13,137.22$, 142.62. Anal. Calcd for $\mathrm{C}_{19} \mathrm{H}_{20} \mathrm{~N}_{2} \mathrm{O}_{4} \mathrm{~S}_{2}: \mathrm{C}, 56.42 ; \mathrm{H}, 4.98 ; \mathrm{N}$, 6.93. Found: C, 56.3; $\mathrm{H}, 5.0 ; \mathrm{N}, 6.9$.

Al(Hg)-Mediated Cleavage of 1i. Recrystallized 1i (715 $\mathrm{mg}, 2 \mathrm{mmol}$ ) was dissolved in $\mathrm{Et}_{2} \mathrm{O}(160 \mathrm{~mL})$, and $\mathrm{H}_{2} \mathrm{O}(1 \mathrm{~mL})$ was added followed by freshly prepared $\mathrm{Al}(\mathrm{Hg})^{15}(0.54 \mathrm{~g}, 20$ $\mathrm{mmol}$ ) in small portions under $\mathrm{CO}_{2}(\mathrm{~g})$ with rapid stirring. After $4 \mathrm{~h}$, when most of the Al had dissolved and TLC indicated only minor amounts of remaining $\mathbf{1 i}$, more $\mathrm{Al}(\mathrm{Hg})(0.27 \mathrm{~g}, 10$ $\mathrm{mmol}$ ) was added as above and al lowed to react overnight, at which time 1i could no longer be detected. The grayish solid material was filtered off with suction and rinsed thoroughly. The clear filtrate was concentrated to $25 \mathrm{~mL}$, diluted with light petrol eum $(25 \mathrm{~mL})$, and further concentrated to preci pitation. After brief cooling, the white solid was collected by filtration, rinsed with light petroleum, and dried to give pure carbazole (313 mg, 94\%) with $\mathrm{mp} 248-249{ }^{\circ} \mathrm{C}$.

Controlled Potential Electrolysis of $11 . \mathrm{A}$ solution of $\mathrm{Et}_{4-}$ $\mathrm{NCl}\left(0.1 \mathrm{M}\right.$; supporting electrolyte) and $\mathrm{Et}_{3} \mathrm{NHCl}(0.05 \mathrm{M}$; proton donor) in MeCN was added to a three-electrode cell of batch type. ${ }^{10 a}$ To its cathodic compartment $\mathbf{1 l}(332 \mathrm{mg}, 1.00$ $\mathrm{mmol}$ ) was added, and a cyclic voltammogram was recorded. The potential was adjusted to a value $50 \mathrm{mV}$ more negative

(14) Curtius, T.; Bottler, H.; Raudenbusch, W. J . Prakt. Chem. 1930 125,380

(15) Smith, M. In Reduction. Techniques and Applications in Organic Synthesis; Augustine, R. L., Ed.; Marcel Dekker, New York, 1968; pp 136-137. 
than that for the CV peak, and the electrolysis was started. Monitoring was by HPLC. When all starting material had disappeared, the content of the cathodic compartment was evaporated at reduced pressure, and the residue was chromatographed on silica using $\mathrm{CH}_{2} \mathrm{Cl}_{2}$ as eluent to give $164 \mathrm{mg}$ (98\%) of carbazole with $\mathrm{mp} 246.5-248{ }^{\circ} \mathrm{C}$. Similar experiments with $\mathbf{1 a}, \mathbf{1} \mathbf{k}$, and $\mathbf{1 m}$ on a $0.1 \mathrm{mmol}$ scale without isolation of indole indicated yiel ds of $92 \%, 80 \%$, and $84 \%$, respectively, as determined by HPLC.

Cleavage of $\mathbf{2 b} / 3 \mathrm{~b}$ with $\mathrm{Mg} / \mathrm{MeOH}$. A. (Typical Experiment without $\mathbf{N H}_{4} \mathbf{C l}$ ). To a solution of $\mathbf{2 b} / \mathbf{3 b}$ (284 mg, 1 $\mathrm{mmol})$ in anhydrous methanol $(8 \mathrm{~mL})$ was added $\mathrm{Mg}$ powder (250 $\mathrm{mg}, 10 \mathrm{mmol}$ ). The resulting mixture was sonicated for $40 \mathrm{~min}$, at which time TLC (A) indicated that all the starting material had disappeared. The reaction was quenched by addition of a saturated solution of $\mathrm{NH}_{4} \mathrm{Cl}(10 \mathrm{~mL})$ and extracted three times with EtOAc $(30 \mathrm{~mL})$. The organic phase was dried $\left(\mathrm{Na}_{2} \mathrm{SO}_{4}\right)$ and evaporated to dryness. The resulting brown residue was purified by flash chromatography (EtOACl cyclohexane 1:3) on a silica gel pad to afford $90 \mathrm{mg}(96 \%)$ of a liquid corresponding to aniline.

B. (Typical Experiment with $\mathbf{N H}_{4} \mathbf{C l}$ ). The same experiment was carried out in the presence of $\mathrm{NH}_{4} \mathrm{Cl}(54 \mathrm{mg}, 1 \mathrm{mmol})$ and stirring at room temperature. When gas evolution ceased, TLC indicated remaining $\mathbf{2} \mathbf{b} / \mathbf{3 b}$, and an extra 5 equiv of $\mathbf{M g}$ powder was therefore added. This was repeated every time gas evolution had ceased until the complete disappearance of the starting material. Workup as above afforded the same amount of aniline.
Selective Cleavage of $3 f$ with $\mathbf{M g} / \mathrm{MeOH}$. Compound $3 f$ (404 mg, $1 \mathrm{mmol}$ ) was added to a suspension of $\mathrm{Mg}$ powder $(250 \mathrm{mg}, 10 \mathrm{mmol})$ and $\mathrm{NH}_{4} \mathrm{Cl}(54 \mathrm{mg}, 1 \mathrm{mmol})$ in dry methanol $(8 \mathrm{~mL})$. The resulting mixture was sonicated for $40 \mathrm{~min}$ at room temperature, at which time TLC on silica ( $\mathrm{A}$ and $\mathrm{CH}_{2-}$ $\mathrm{Cl}_{2} / \mathrm{MeOH} 3: 1$ ) indicated that all the starting material had been consumed. The reaction mixture was then extracted five times with EtOAc ( $40 \mathrm{~mL}$ each), and the organic phase was dried $\left(\mathrm{Na}_{2} \mathrm{SO}_{4}\right)$ before being evaporated to dryness. The white powder obtained (200 mg, 93\%) was suspended in dry $\mathrm{Et}_{2} \mathrm{O}$ and sonicated for $5 \mathrm{~min}$ to afford upon standing a very fine white solid with $\mathrm{mp} 120-121{ }^{\circ} \mathrm{C}$ corresponding to Ts-NH$\left(\mathrm{CH}_{2}\right)_{2} \mathrm{NH}_{2}$.

Acknowledgment. This work was supported by the Swedish Natural Science Research Council (NFR), the Swedish Research Council for Engineering Sciences (TFR), Carl Tryggers Stiftelse, Astra Draco AB, and the Fundaçao para a Ciência ea Tecnologia (Portugal). B.N. gratefully acknowledges the RSC for a journals grant for international authors and the ISP for a fellowship, as well as the University of Yaoundé I for a leave of absence.

Supporting Information Available: Full experimental details for all new compounds $\mathbf{1}-\mathbf{3}$ (9 pages). This material is available free of charge via the Internet at http://pubs.acs.org.

J O990695Q 